\title{
IMPLICAÇÕES TEÓRICO-PRÁTICAS DO BI- NÔMIO CUIDAR-EDUCAR NA FORMAÇÃO DE PROFESSORES DE EDUCAÇÃO INFANTIL
}

\section{THEORETICAL-PRACTICAL IMPLICATIONS OF CARING-EDUCATING IN THE EDUCATION OF TEACHERS FOR CHILDHOOD EDUCATION}

Heloisa Helena Oliveira de AZEVEDO*

Resumo: Este texto aborda a problemática da separação entre cuidar-educar na Educação Infantil e na formação de seus professores. Partimos de uma revisão histórica sobre a origem e desenvolvimento das instituições de Educação Infantil no Brasil, as formas de atenção voltadas à criança e as mudanças nas concepções de infância e Educação Infantil, para apresentar os elementos que nos ajudam a compreender como foi sendo construído o binômio cuidar-educar. Com base em tal revisão e em entrevistas semi-estruturadas com formadores de profissionais de educação infantil, o problema da separação entre cuidado e educação foi analisado, com vistas a desvendar sua origem e conseqüências para a área. Ao final, usando a concepção histórico-crítica de educação e a abordagem histórico-cultural de desenvolvimento humano como referenciais teóricos de análise, ressaltamos suas implicações para a Educação Infantil e para a formação de professores que atuam (ou atuarão) nessa modalidade de ensino, apontando alternativas de enfrentamento do problema.

Palavras-chave: Formação Docente. Educação Infantil. Cuidar-educar.

\footnotetext{
* Doutora em Educação pela Universidade Metodista de Piracicaba (UNIMEP), Docente do CCSA/ PPGE e Faculdade de Educação da Pontifícia Universidade Católica de Campinas (PUCCAMP). hazevedo@puc-campinas.edu.br
} 


\begin{abstract}
This article discusses the separation between caring and educating in Childhood Education and in Teacher Education. The article starts with a historical review about the origins and development of Childhood Education institutions in Brazil, the forms of attention given to children and the changes in the concepts of childhood and Childhood Education. This is done to present the elements that help us understand how the term caring-education has developed. Based on the review and on semi-structured interviews with those responsible for the education of the professionals involved in childhood education, the problem with the separation between caring an educating was analyzed, trying to unravel its origin and consequences. Using the historical-cultural conception of human development as the theoretical framework for the analysis, it is pointed out its implications for Childhood education and for Teacher Education and also alternative ways to deal with the problem.
\end{abstract}

Keywords: Teacher Education. Childhood Education. Caring-educating.

\title{
INTRODUÇÃO
}

O profissional da Educação Infantil vem, ao longo da sua trajetória, experimentando diferentes exigências em relação à sua atuação. Tais exigências vêm sendo feitas em função da origem e determinação social das instituições de atendimento infantil e das transformações históricas nas sociedades que, por sua vez, provocaram mudanças nas concepções de infância e de Educação Infantil.

A concepção de criança e a forma de atendimento a ela dispensado também vêm sofrendo mudanças significativas desde o início da Idade Moderna. Mudamos de uma concepção de criança como um adulto em miniatura para uma de criança como ser histórico e social, de uma mãe indiferente para uma mãe coruja, de um atendimento feito em asilos, por adultos que apenas gostassem de cuidar para um feito em uma instituição educativa, por um profissional da área do qual se exige formação adequada para lidar com as crianças. 
A literatura da área tem apontado para a necessidade de se construir essa profissão e, historicamente, as propostas para a Educação Infantil têm revelado um perfil de profissional que está em consonância com as várias tendências pedagógicas que caracterizam, ainda hoje, o atendimento à Educação Infantil no Brasil. Identificadas como romântica, cognitiva e crítica, essas tendências foram sendo criadas em diferentes épocas, influenciando, também, na formação dos profissionais que atuam na área. Cada tendência organiza-se com base nas concepções de criança, professor e educação escolar dos estudiosos de cada época que as representam, tendo sido, assim, sistematizadas e denominadas a partir de estudos desenvolvidos por pesquisadores contemporâneos.

As referências históricas nos revelam e nos ajudam a compreender como foi sendo construída a idéia equivocada de que é possível oferecer à criança um atendimento que privilegie ora um ora outro aspecto desse atendimento, como se houvesse possibilidade de apenas "cuidar" das crianças ou apenas "educá-las".

Ao longo dos dez últimos anos a discussão sobre a necessidade de integrar cuidado e educação na Educação Infantil tem sido feita exaustivamente, tanto na literatura da área quanto em fóruns nacionais de debates sobre educação. No entanto, os vários trabalhos referidos nesses estudos e fóruns apontam que ainda não conseguimos resolver o problema da separação cuidar-educar, o que nos remete à idéia de que a persistência, ou a superação dessa separação tem na formação inicial uma forte aliada.

\section{SEMPRE EXISTIU INFÂNCIA? O SURGIMENTO DE UM CONCEITO}

Etimologicamente, a palavra "infância", oriunda do latim, significa "incapacidade de falar" e era atribuída em geral ao período que se chama de primeira infância, às vezes era vista como se estendendo até os 7 anos, que representariam a passagem para a idade da razão (KUHLMANN JR., 1998, p. 16).

O termo "infância" é, hoje, para nós, bastante conhecido e corriqueiro. Em nossa sociedade é usado para identificar a fase inicial da vida do indivíduo, período em que ele ainda necessita de cuidados e atenção devido ao seu pouco tempo de estada no mundo. Por outro 
lado, esse termo e suas derivações (como "infantil" ou "infantilidade") são utilizados, em determinadas situações, de modo pejorativo, como, por exemplo, para fazer uma crítica negativa ao comportamento de um adulto que tenha agido de forma imatura, instintiva, sem pensar, ou seja, tal qual agiria um indivíduo de pouca idade, ainda desprovido de razão, inexperiente, ingênuo, frágil - uma criança.

A visão, em geral, que temos hoje da criança é a de alguém diferente do adulto não só no tamanho, mas também na pouca experiência de vida. Vemos essa criança como ingênua, frágil e, por esse motivo, entendemos que ela precisa ser cuidada, principalmente nos primeiros anos de vida, até que vá amadurecendo, tornando-se independente fisicamente e capaz de agir de modo racional.

Considerada por muitos como período de transição para a adolescência e juventude e marcada pela brevidade, a infância - do vocabulário latino infantia: "idade até os sete anos", caracterizada pela "falta de eloqüência" e "dificuldade de explicar-se" - é tida como um período da vida humana em que a criança é incapaz de falar de si mesma e de discernir, encontrando-se totalmente dependente dos adultos (MONARCA, 2001, p. 1-2).

Mas, será que essa é a única visão que nossa sociedade tem de criança? Evidentemente, falávamos de uma criança inserida em um determinado contexto histórico, cultural, político e econômico. Porém, se mudarmos de contexto, encontraremos outras crianças, com experiências de vida diferenciadas, as quais, embora também pequenas em sua estatura, talvez não sejam concebidas como tão inexperientes e ingênuas.

Então, as crianças não são todas iguais? Não existe um modelo padrão de criança? Nem todas vivenciam a sua infância de forma feliz e prazerosa como a sociedade contemporânea costuma pregar? Sendo assim, podemos dizer que não existe uma, mas várias concepções de criança?

Segundo Prout e James (apud HEYWOOD, 2004, p. 12), “a imaturidade das crianças é um fato biológico, mas a forma como ela é compreendida e se lhe atribuem significados é um fato da cultura." Heywood (2004, p. 21) complementa essa idéia ressaltando que a criança é um constructo social que se transforma com o passar do tempo e, não menos importante, varia entre grupos sociais e étnicos, 
dentro de qualquer sociedade.

O início da era moderna marcou um novo lugar para a criança e a família. A emergência do conceito de infância, (...) geralmente é localizada no século XVIII, com o triunfo do individualismo burguês no ocidente e de seus ideais de felicidade e emancipação (GAGNEBIN, 1997, p. 83). A referida autora aponta o livro Emílio (de 1762), de Jean Jacques Rousseau, como marco privilegiado dessa - nossa - concepção moderna de infância. Tal obra transforma a prática pedagógica de boa parte da elite esclarecida da época.

No momento em que a criança começa a ser associada à idéia de inocência, de pureza, passa-se também a defender a necessidade de "protegê-la". É preciso agir de forma a não ter o que corrigir na fase adulta. Isso significa, então, a necessidade de isolá-la e submetêla à vigilância contínua para preservá-la do lado impuro da vida, e o espaço destinado a realizar tal tarefa é a "escola".

Outras modificações ocorreram, também, pelo aspecto afetivo. O meio mais coletivo em que a criança vivia antes de ser enclausurada na escola, a deixava menos vulnerável. Os papéis afetivos não eram rígidos. Hoje, ao contrário, a família se coloca enquanto a única estrutura onde se processam contatos afetivos. A família moderna monopoliza essa afetividade (ARIÈS, 1981).

Essa carga emocional colocada sobre a criança se manifesta de alguma forma na escola, que precisa pensar formas de considerá-la em suas propostas e currículos. De acordo com a concepção de infância vigente na época, as instituições de atendimento infantil tinham como principal tarefa oferecer à criança proteção, cuidados de higiene, alimentação e saúde, ou seja, responsabilizar-se pelo seu bem-estar durante o período em que lá era deixada pelos pais.

A concepção de criança enquanto ser necessitado apenas de cuidado e proteção fundamenta o atendimento a elas oferecido ao longo de toda a idade moderna, passando, mais adiante na história, por algumas modificações, mas organizadas de acordo com a classe social de origem da criança. Além da existência das creches para "cuidar" dos filhos de famílias mais pobres, surgem os jardins-de-infância, instituições pré-escolares que, com suas propostas "pedagógicas", atendiam os filhos das famílias das elites.

É importante ressaltar que, segundo Kramer (1992), tendências pedagógicas (romântica, cognitiva e crítica) foram se construindo apoiadas nas mudanças na concepção de criança. Entretanto, isso não 
significa que com o surgimento de uma nova concepção ou tendência houvesse o desaparecimento de outra. Cada tendência organiza-se com base nas concepções de criança, professor e educação escolar dos estudiosos de cada época que as representam, tendo sido sistematizadas e denominadas como tal a partir de estudos desenvolvidos por pesquisadores contemporâneos.

Esta breve retomada histórica traz à tona aspectos relevantes não só sobre as mudanças na concepção de criança, como, também, sobre a transformação ocorrida no espaço e nas propostas de atendimento (escolar ou não) a ela oferecida. Num olhar retrospectivo e ampliado para além da realidade brasileira, a impressão que nos dá é a de que, para a maioria das crianças, a infância volta a ser uma fase bastante reduzida. Há hoje, como na velha sociedade tradicional, uma precocidade na passagem ao mundo dos adultos, do trabalho, do abandono, da exclusão. Isso, entretanto, não significa uma volta aos sentimentos das antigas sociedades, pois para muitas crianças a passagem hoje é marcada pela violência, pela agressão e pelo desrespeito às suas necessidades e direitos de cidadã.

\section{ENTRE A ASSISTÊNCIA E A EDUCAÇÃO: A HISTÓRIA DO ATENDIMENTO À INFÂNCIA NO BRASIL}

Como viveram ou eram vistas as crianças em vários momentos da história do Brasil? Fazer um resgate da história da criança brasileira é encarar um passado trágico, o qual fez parte da vida de milhares de meninos e meninas, segundo Del Priore (1998, p. 8):

O abandono de bebês, a venda de crianças escravas que eram separadas de seus pais, a vida em instituições que no melhor dos casos significavam mera sobrevivência, as violências cotidianas que não excluem os abusos sexuais, as doenças, queimaduras e fraturas que sofriam no trabalho escravo ou operário foram situações que empurraram por mais de três séculos a história da infância no Brasil. Contudo, se é verdade que dessa história surge uma imagem de autoritarismo e indignidade imposta por adultos às crianças, surge também uma história de amor materno e paterno, de afeto e de humanidade das inúmeras pessoas que acima de preconceitos e interesses mesquinhos, deixaram-se sempre sensibilizar com aquelas que, antes de tudo, são os mais carentes e indefesos dos seres humanos. 
Nossas primeiras idéias/imagens/sentimentos em relação à criança brasileira sofreram grande influência dos europeus, através dos missionários jesuítas que aqui chegaram no século XVI. Aos olhos destes, a criança brasileira (índia, negra, mestiça) se assemelhava aos anjos, seres bons puros e inocentes. Era o "papel em branco" em que os jesuítas inscreveriam a sua cultura, com base em fortes conteúdos de educação moral e religiosa aos quais as crianças eram submetidas antes que o "pecado" se instalasse em suas almas.

Tal influência européia continuou presente por muito tempo na nossa história, quando da criação dos "jardins de infância" nos moldes dos kindergartens, "herança" que, ainda hoje, se observa nas propostas pedagógicas de instituições de atendimento infantil, concepções e práticas de profissionais da área, especialmente em nosso país.

O atendimento à infância no Brasil mostra tendências diferenciadas em função das concepções de infância que o orientavam em cada momento histórico. Num primeiro período, demarcado entre o "descobrimento" até a fase de 1930, inicia-se a valorização gradativa da infância e o reconhecimento da necessidade de atendê-las. No segundo período, que vai de 1930 a 1980, concretizam-se trabalhos de assistência social e educacional à infância, tendo em vista, principalmente, o "desenvolvimento nacional" (KRAMER, 1992). Num terceiro momento evidenciam-se alguns importantes fatos/eventos relativos à Educação Infantil, que ocorreram na fase de 1980 até a atualidade.

A visão da infância no Brasil colônia era a de que precisava ser salva dos maus comportamentos adultos. Os missionários da Companhia de Jesus, os jesuítas, recém-chegados na Terra de Santa Cruz, no século XVI, tinham objetivos bem definidos. O primeiro deles era ordenar a colônia para que tivesse a marca civilizatória da metrópole; e o segundo, ordenar as almas indígenas para que recebessem as sementes da palavra de Deus, por eles trazida. "Transformação da paisagem natural e também dos nativos em cristãos: esta era a missão" (DEL PRIORE, 1998, p.11).

De acordo com a referida autora, fato importante daquela época, no que se refere à infância, foi a elaboração quinhentista e européia dos primeiros modelos ideológicos sobre a criança. A igreja católica foi a responsável pela disseminação das duas imagens de criança: a da criança mística e a da criança que imita Jesus. "Essa 
imagem da infância era um afresco melhorado e espiritualizado da infância estudada por Áries, para o final da Idade Média, e que via a criança enquanto um ser anedótico e engraçadinho" (DEL PRIORE, 1998, p. 12).

Os jesuítas trouxeram a mentalidade européia da criança enquanto ser gracioso e vulnerável, o que contribuiu para que enxergassem nos pequenos indígenas - ou "muchachos", como os chamavam - um inocente... mui elegante e formoso, ou ainda, mui bons e mui bonitos.

O projeto jesuítico de aculturação dos índios começa a falhar quando esses pequenos chegam à puberdade e começam a apoderarse de si. Era a idade ingrata e perigosa aos olhos dos jesuítas, que afirmavam que quanto mais modestos e obedientes fossem os índios aos costumes cristãos quando pequenos, ao chegar à puberdade se tornavam mais corruptos, sem vergonhas e maus. A puberdade marca, por fim, a expulsão do paraíso prometido pelos jesuítas, onde na realidade eles não queriam ter nada mais do que crianças dóceis e obedientes. Assinala-se, então, o abandono do jardim de infância (DEL PRIORE, 1998).

Tal realidade fez com que os objetivos do projeto missionário jesuítico passassem por algumas mudanças. Não se pretendia mais formar cristãos, passando-se a investir mais na instrução. A partir de então, a história da criança brasileira, especialmente aquelas das classes menos favorecidas economicamente, desenvolveu-se em meio ao descaso, à discriminação e ao abandono. Até meados do século XIX, isto é, desde o descobrimento até 1874, pouco se fazia no Brasil pela infância desditosa, tanto no que tange à proteção jurídica quanto às alternativas de atendimento existentes (KRAMER, 1992).

Como já dissemos anteriormente, a história da criança brasileira é uma história de abandono, fenômeno que se observou aqui desde a colonização. Segundo os estudos de Marcilio (1997), foi criada, ainda na colônia (1726), a Roda dos Expostos ${ }^{1}$. Tal sistema perdurou durante mais de dois séculos, sendo a única instituição de assistência à criança abandonada no Brasil. Sendo o Brasil o último país a abolir a chaga da escravidão, foi ele igualmente o último a acabar com o triste sistema da roda dos enjeitados (MARCILIO, 1997).

${ }^{1}$ Sistema de atendimento à criança abandonada inventado na Europa medieval (Itália/Lisboa), também chamado de Roda dos Enjeitados (MARCILIO, 1999, p.51). 
Segundo Kramer (1992), o atendimento à criança pequena naquele período era desenvolvido em grande parte por associações beneficentes, ou seja, atendiam-se crianças das classes menos favorecidas social e economicamente (filhos da união de escravos ou destes com senhores), crianças que não haviam nascido de uma família padrão.

De acordo com KUHLMANN JR (1998), as creches, naquele período, eram vistas como asilos infantis, pois as preocupações com o atendimento à infância se voltavam para os filhos de escravas, os quais, após a lei do ventre livre, passaram a trazer problemas para as donas de casa, relacionados principalmente à educação. Acreditavase que se as crianças filhas de escravas não recebessem assistência e educação, poderiam ser convertidas em inimigos da tranqüilidade futura. O autor ressalta, ainda, que as creches surgiram no Brasil no final do século XIX, mais para atender às mães trabalhadoras domésticas do que as operárias industriais, pois ainda não havia uma demanda efetiva pelo trabalho feminino nas indústrias. Essa demanda existia nos países europeus, especialmente na França e, por conta disso, aqui no Brasil, a creche era proposta em nome da ampliação do trabalho industrial feminino.

As instituições de atendimento infantil foram surgindo na perspectiva de atendimento aos pobres. Tinham caráter de guarda e preocupavam-se apenas com a alimentação, higiene e segurança física das crianças. Tal atendimento contava com as chamadas criadeiras, amas-de-leite ${ }^{2}$ ou mães mercenárias, com precárias condições de higiene.

Mesmo havendo posicionamentos declaradamente contrários à criação dos jardins-de-infância, era crescente o interesse pela infância desprotegida. Entretanto, as instituições de atendimento eram insuficientes e não havia um propósito claro para tal atendimento. Por isso, a mobilização de grupos interessados no atendimento às crianças pequenas resultou na criação do Instituto de Proteção e Assistência à Infância do Brasil, em 1899, com os objetivos de:

(...) atender aos menores de oito anos, elaborar leis que regulassem a vida e a saúde dos recém-nascidos; regulamentar o serviço das

\footnotetext{
${ }^{2}$ As amas-de-leite eram em sua quase totalidade mulheres extremamente pobres, solteiras, ignorantes e residentes nas cidades. Algumas eram mulheres casadas ou escravas. Como recebiam uma quantia para cuidar das crianças abandonadas, era comum não declararem a morte de uma criança à Santa Casa e continuarem por algum tempo recebendo o seu salário de ama, como se o bebê estivesse vivo. As Misericórdias não tinham como controlar as crianças que protegiam (MARCILIO, 1998).
} 
amas de leite, velar pelos menores trabalhadores e criminosos; atender às crianças pobres, doentes, defeituosas, maltratadas e moralmente abandonadas; criar maternidades, creches e jardins de infância (KRAMER, 1992, p. 52).

A criação do Instituto desencadeou a criação de várias outras instituições de atendimento infantil, como creches para filhos de operários e jardins de infância. A concepção de infância que orientava essas instituições era a da criança como um ser frágil e necessitado de cuidados e proteção. Assim, a instituição precisava garantir à sociedade a permanência e a estabilidade indispensáveis ao seu progresso e aos engrandecimentos futuros.

Ao lado dessas iniciativas de atendimento à infância pobre, criaram-se também instituições pré-escolares, sob o discurso de um atendimento pedagógico. Segundo Kuhlmann Jr. (1998, p. 83-84), esse termo foi utilizado com a intenção de legitimar os interesses de um atendimento infantil privado, como explicita o autor:

A preocupação daqueles que se vinculavam às instituições préescolares privadas brasileiras era com o desenvolvimento das suas próprias escolas. Nota-se, entre eles, a utilização do termo 'pedagógico' como uma estratégia de propaganda mercadológica para atrair as famílias abastadas, como uma atribuição do jardim de infância para os ricos, que não poderia ser confundido com os asilos e creches para os pobres.

Tais propostas “pedagógicas” eram vistas como uma imitação do ensino pré-escolar europeu (França, Suíça, Áustria e Alemanha), os chamados kindergarten (jardins-de-infância), que eram as instituições pré-escolares procuradas pelas famílias das elites. Essas instituições tinham orientação pedagógica froebeliana, que foi adotada também pelas pré-escolas brasileiras privadas. Por outro lado, as iniciativas de atendimento infantil, centradas no cuidado e na proteção às crianças pobres, criaram um estigma social para as instituições populares: o de que eram destinadas ao atendimento de crianças das classes subalternas.

A história da assistência tem sido também a da produção de uma imagem do pobre como ameaça a ser controlada. As instituições cumpririam uma função apaziguadora. Interpreta-se a pobreza a 
partir da generalização de características parcializadas. Essa lógica ainda se faz presente quando se reduz a história da infância à da infância abandonada, quando a criança pobre é identificada como 'menino de rua', que, por sua vez, torna-se sinônimo de 'trombadinha', ou 'menor infrator', reproduzindo a concepção de pobreza forjada nos moldes das concepções assistenciais do início do século. (KUHLMANN JR., 1998, p. 28)

A mesma equipe fundadora do Instituto de Proteção e Assistência à Infância do Brasil criou, em 1919, o Departamento da Criança no Brasil, criado e mantido em termos de recursos por Moncorvo Filho, sem receber qualquer auxílio do Estado ou da municipalidade (KRAMER, 1992). Tal fato começa a retirar as autoridades governamentais da inércia em que se encontravam frente ao atendimento à infância brasileira.

Pode-se dizer que a entrada do governo no atendimento à criança tinha interesses políticos bem definidos, instalando, por isso, um novo sentimento (concepção) em relação à criança. A concepção brasileira de criança, na sua origem, é a de um ser com características divinas (criança $=$ menino-Jesus) que, mais adiante, começa a ser percebido como um ser puro e frágil que precisa ser protegido dos males do mundo.

Conseqüentemente, o atendimento à criança passa a ter outro significado. A educação que era elitizada passava a figurar como possibilidade de ascensão social. O discurso de uma educação democrática defendia, entre outras coisas, o direito de todas as crianças à educação. Isso tudo tinha como pano de fundo o Movimento Escolanovista, no início do século $\mathrm{XX}$, que despontava como inovação no cenário educacional brasileiro, incluindo uma forte dose de psicologização no trabalho educativo.

A partir da segunda metade do século XIX e durante todo o século XX, período em que se consolidou o regime republicano em nosso país, conferiu-se uma maior visibilidade e centralidade à infância, colocando-se em primeiro plano a problemática relativa ao cultivo das gerações mais novas e objetivando sua inserção na esfera pública, isto é, no mundo dos adultos (MONARCA, 2001). A infância, então, passa de abandonada a centro das atenções no que tange aos interesses governamentais, pois o investimento em seu atendimento significava benefícios políticos ao Estado, o que acentuou ainda mais, 
Implicações teórico-práticas do binômio cuidar-educar...

nos anos subseqüentes, a participação dessa esfera no atendimento à criança no Brasil.

De acordo com Kuhlmann Jr. (1998, p.60),

No fim do século XIX e início do século XX (...) criaram-se leis e propagaram-se instituições sociais nas áreas da saúde pública, do direito da família, das relações de trabalho, da educação. As instituições jurídicas, sanitárias e de educação popular substituíam a tradição hospitalar e carcerária do Antigo Regime. São iniciativas que expressam uma concepção assistencial a que denominamos 'assistência científica' - por se sustentar na fé, no progresso e na ciência característica daquela época.

No período citado, aumentou também a criação de creches junto às indústrias, resultante de recomendações freqüentes nos congressos que abordavam a assistência à infância, como forma de regulamentar as relações de trabalho, particularmente quanto ao trabalho feminino. São criados os parques infantis para os filhos de operários e os jardins de infância para os filhos das camadas privilegiadas. Essa educação assistencialista, destinada às camadas mais pobres, tinha o mérito de retirar as crianças das ruas, mas, por outro lado, oferecia um atendimento de baixa qualidade:

(...) previa-se uma educação que preparasse as crianças pobres para o futuro 'que com maior probabilidade lhes esteja destinado'; não a mesma educação dos outros, pois isso poderia levar essas crianças a pensarem mais sobre sua realidade e a não se sentirem resignadas em sua condição social (KUHLMANN JR., 1998, p. 183).

Considerando-se a concepção de criança e o objetivo das instituições de atendimento infantil em nível público, nesse período, os adultos que lidavam com as crianças eram pessoas que não tinham qualquer qualificação, bastava querer e gostar de crianças para delas cuidar.

No início do século XX, o discurso médico de preocupação com a precariedade de vida das camadas populares e da sua marginalização cultural estabelece como objetivo da educação a compensação das carências bio-psico-sociais apresentadas no desenvolvimento da criança, de forma a prepará-la para que não fracassasse nas etapas escolares posteriores. 
Essa concepção de Educação Infantil com função preparatória para as séries iniciais do $1^{\circ}$ grau reforçou o atendimento de cunho compensatório. A crítica à educação compensatória trouxe à tona seu caráter assistencialista, discriminatório. Nesse contexto, o assistencialismo foi configurado como uma proposta educacional específica para esse setor social, dirigida para a submissão não só das famílias, mas também das crianças das classes populares (KUHLMANN JR., 1998, p. 182).

As creches e pré-escolas iniciaram seu processo de expansão na década de 70. É característica desse período a ênfase ao assistencialismo no atendimento às camadas mais pobres da população. As medidas assistenciais do governo, como, por exemplo, a merenda escolar, eram planejadas e postas em prática em detrimento da melhoria do salário dos professores e da destinação de mais verbas para a educação, que eram as principais críticas dos movimentos de reivindicação dos educadores, como ressalta Kuhlmann Jr. (1998, p. 198-199).

Queria-se defender a qualidade do ensino e a culpa de sua queda parecia ser por conta de a escola preocupar-se com a nutrição e não com a educação. É nesse contexto que 'educação' passou a ser vista como oposto de 'assistência' (...) passou-se a defender que as creches - e também a pré-escola que atendia as classes populares - precisavam de um 'projeto educacional'.

Esse período é também marcado pelo surgimento de várias propostas de atendimento à infância, em função da multiplicidade de órgãos criados para tal. A causa da criança despertava o interesse de autoridades oficiais e consolidava iniciativas particulares. (KRAMER, 1992).

A família da criança, nesse contexto, era culpabilizada pelo abandono e descuido com as crianças, pois sua situação social não era considerada nas análises do governo. Ao atribuir essa culpa à família, retirava-se a responsabilidade do Estado de oferecer tal atendimento. Colocando unicamente para a família a responsabilidade pelas suas crianças, o Estado passa a assumir um papel de redentor das crianças abandonadas, ou seja, começa a pregar a imagem da criança como o futuro do país. A partir de então, as iniciativas governamentais de atendimento à infância seriam de cuidado e proteção da criança, que 
seria a esperança de um mundo melhor (KRAMER, 1992).

Como pudemos constatar, historicamente, atribuiu-se às instituições de Educação Infantil uma função unicamente assistencial, devido à sua vinculação administrativa aos órgãos de assistência. Desde sua origem, elas foram definidas como espaços de atendimento para crianças pobres que, por sua vez, eram vistas como seres necessitados apenas de cuidados físicos e proteção.

O reconhecimento pela Constituição de 1988 e, posteriormente, pela LDB, do direito das crianças de $\mathrm{O}$ a 6 anos de idade à educação, embora possa ser considerado como superação de um obstáculo, não significa que é apenas a partir desse momento que as instituições infantis passam a ter a "função educativa".

A esse respeito, KUHLMANN JR (1998) afirma que as creches e pré-escolas assistencialistas foram concebidas e difundidas como instituições educacionais, o que invalida a idéia de que elas precisariam deixar de ser "assistenciais" para se tornarem "educacionais". A idéia de que tornar as creches espaços educativos seria imprimir algo "novo" às instituições de Educação Infantil acabou por se tornar a tônica da reformulação de grande número de propostas de atendimento dessa faixa etária nos dias de hoje. Na verdade, as propostas se diziam "inovadoras" pelo simples fato de deixarem de ser assistenciais para se tornarem educativas.

Sobre isso, o mesmo autor ressalta que:

Um estudo mais cauteloso e atento das fontes mostra-nos que a história não é bem essa. Ao anunciar o educacional como sendo o 'novo' necessário, afirma-se a 'educação' como o lado do 'bem' e a assistência como o império do 'mal', assim como se estabelece uma oposição irreconciliável entre ambas. (...) Não são as instituições que não tem caráter educacional e sim os órgãos públicos da educação, os cursos de pedagogia e as pesquisas educacionais que não se ocuparam delas por um longo período (KUHLMANN JR., 1998, p. 202).

A partir da década de 1980, algumas mudanças foram feitas em relação ao atendimento à criança pequena. A Constituição de 1988, o Estatuto da Criança e do Adolescente - ECA (1990), o Encontro Técnico sobre Política de Formação do Profissional de Educação Infantil (1994), a Lei de Diretrizes e Bases da Educação Nacional (1996), o 
Referencial Curricular Nacional para a Educação Infantil (1998), as Diretrizes Curriculares Nacionais para a Educação Infantil (1998) e Os Referenciais para Formação de Professores (1999) contribuíram para que $\mathrm{o}$ atendimento às crianças de $\mathrm{O}$ a 6 anos de idade e a formação profissional daqueles que com elas atuam, merecessem mais atenção da legislação. Essas conquistas, em termos legais, inserem a criança de $\mathrm{O}$ a 6 anos no interior do sistema escolar, na educação básica, garantindo o direito da criança à educação e, conseqüentemente, impondo ao Estado a obrigatoriedade de oferecer instituições para essa faixa etária (KISHIMOTO, 1999).

Em função dessa nova realidade, a concepção de criança também passa por reformulações. O desenvolvimento de pesquisas na área contribuiu de forma significativa para que se começasse a construir outro olhar sobre a criança, reconhecendo-a como um ser histórico e social, inserida em uma determinada cultura, um ser em desenvolvimento, que já faz parte da sociedade, que já é cidadã.

Conseqüentemente, também mudou nossa maneira de lidar com as crianças. Se no início se pensava em apenas "cuidar" delas, mais tarde a proposta era a de educá-la", em resposta às transformações e exigências políticas que se faziam, provocando uma dicotomia nesse atendimento institucionalizado que já ocorria, de fato, em termos sociais. Ou seja, às crianças das classes populares era oferecido atendimento assistencial (cuidar) e às da elite se oferecia atendimento educacional (educar) e o aprendizado de leitura, escrita e conteúdos escolares. Essa separação também se dava pela idade das crianças, oferecendo-se às de $\mathrm{O}$ a 3 anos apenas cuidados e às de 4 a 6, educação, nos moldes escolares.

Evidentemente, não podemos desconsiderar que também se fizeram mudanças quanto ao perfil dos adultos que trabalham com a Educação Infantil, provocando o estabelecimento de exigências quanto à formação adequada dos profissionais que atuam com as crianças de O a 6 anos de idade. A história de conquistas e retrocessos que hoje fazem parte dessa realidade são elementos importantes para nossa reflexão sobre o problema da separação cuidar-educar na formação dos professores de Educação Infantil, posto que seja nessa trajetória que vai se construindo a visão dissociada de cuidado e educação. 
Implicações teórico-práticas do binômio cuidar-educar...

\section{AS IMPLICAÇÕES DO BINÔMIO CUIDAR-EDUCAR}

Nossa história nos mostra que existe uma dupla imagem do adulto que lida com crianças na instituição. A primeira imagem é a do "adulto maternal", aquele que apenas "cuida" de crianças de $\mathrm{O}$ a 3 anos, do qual não se exigiu, por muito tempo, formação adequada. A outra imagem é a da profissional "professora", formada para "ensinar" as crianças de 4 a 6 anos. Podemos dizer também que as concepções de criança e de Educação Infantil são as grandes estruturadoras da ação dos profissionais da Educação Infantil, pois de acordo com a maneira como concebem a criança é que eles planejam e desenvolvem o trabalho com ela.

Temos constatado ao longo de nossos estudos sobre a formação de professores da Educação Infantil que essa dualidade profissional existente na área, construída historicamente, tem sido ainda propalada na formação docente inicial, através das concepções de criança e de Educação Infantil dos formadores, configurando-se num elemento reforçador da visão dicotômica de cuidado e educação.

As melhorias que têm sido feitas nessa formação, em termos curriculares ou estruturais, não podem ocorrer de forma isolada da luta por um reconhecimento, em nível social, dos profissionais da Educação Infantil. Tardif (2002) denomina de "mentalismo" as intenções de reduzir os saberes docentes, exclusiva ou principalmente, a processos mentais (representações, crenças imagens, processamento de informações, esquemas, etc.) cujo suporte é a atividade cognitiva dos indivíduos.

Nesse sentido, consideramos que a formação inicial tem uma parcela de contribuição bastante significativa a oferecer, no que se refere à construção da profissionalidade dos professores da Educação Infantil, a qual é definida por Sacristán (1991) como a afirmação do que é específico na acção docente, isto é, o conjunto de comportamentos, conhecimentos, destrezas, atitudes e valores que constituem a especificidade do ser professor.

Professores capazes de construir proposta pedagógica com clara intencionalidade educativa, compreendendo a importância de seu papel social no exercício da docência, independentemente da idade da criança, necessitam de uma formação teórica e prática solidamente fundamentada, que lhes permita esclarecer, em primeiro lugar, suas próprias concepções e valores, tendo autonomia para fazer suas op- 
ções, ou melhor, para sentir-se bem na sua pele.

Um dos entraves para o alcance de um ideal formativo é a desvinculação de nossa formação profissional dos condicionantes sociais que a envolvem. Também a falta de uma maior unidade entre os profissionais do Magistério quanto aos aspectos que interferem na profissão - que vão desde as condições dignas de trabalho e remuneração até o reconhecimento social da profissão - dificulta ao professor o relacionamento do seu fazer com os diversos contextos que definem e influenciam a prática pedagógica.

Sobre isso, Sacristán (1991: 74) ressalta que:

Uma correcta compreensão do profissionalismo docente implica relacioná-lo com todos os contextos que definem a prática educativa. O professor é responsável pela modelação da prática, mas esta é a intersecção de diferentes contextos. O docente não define a prática, mas o papel que aí ocupa; é através da sua actuação que se definem e concretizam as múltiplas determinações provenientes dos contextos em que participa.

Embora consideremos que as mudanças realizadas até o momento são válidas e têm contribuído para ampliar o universo formativo dos professores, elas não têm alcançado o resultado esperado no que se refere à superação da separação cuidar-educar. Portanto, ainda nos encontramos presos ao referido problema.

Em recente pesquisa por nós realizada, foi possível constatar que a persistência do problema da separação entre cuidar-educar está relacionada ao não reconhecimento social dos profissionais docentes. Ou seja: a concepção dicotômica de cuidado e educação, que permeia o imaginário dos professores de Educação Infantil, reforça uma imagem de pouco (ou nenhum) "status social", o que os leva a buscarem semelhanças com as práticas pedagógicas do Ensino Fundamental, uma vez que nesse nível de ensino o professor "ensina conteúdos" e não apenas "cuida" das crianças.

Os professores da Educação Infantil consideram que o fato de se assemelharem aos professores do Ensino Fundamental lhes proporcionaria um status social mais elevado. Entretanto, não podemos deixar de ressaltar que as práticas pedagógicas desenvolvidas no Ensino Fundamental precisam ser igualmente repensadas.

Temos constatado também que os cursos de Pedagogia que 
formam professores para a Educação Infantil e o Ensino Fundamental têm enfatizado a preparação teórica em detrimento de uma adequada relação dessa teoria com o contexto da prática, isto é, com os possíveis espaços de atuação desses profissionais. Nos cursos de formação inicial, em geral, trata-se da teoria sem a preocupação de relacioná-la com a prática, pressupondo-se que será oferecida aos alunos uma disciplina que vai dizer como se deve agir na prática. É a expressão do modelo de racionalidade técnica na formação docente.

A afirmação acima reflete a opinião de um dos formadores de professores entrevistados na referida pesquisa, para quem essa desarticulação teórico-prática na formação inicial ocorre principalmente porque:

(...) há disciplinas dentro do curso que têm esse caráter de aplicação, elas são importantes, mas as disciplinas teóricas são fundamentais, são elas que vão desenvolver o raciocínio abstrato. (...) $A$ teoria é o lugar da abstração, é o lugar da gente sonhar, da gente poder se soltar das amarras do cotidiano e aí a nossa imaginação, a nossa reflexão crítica sobre aquilo que vem como proposta vai poder reverter depois numa proposta da atuação prática. Às vezes eu acho que talvez fosse necessário mais teoria para que as pessoas pudessem chegar nesse nível de trabalhar com essas questões. (...), as experiências práticas na formação são focadas muito no campo didático-pedagógico e das metodologias e isso acaba por empobrecer esse universo teórico (...).

Se a realidade atual necessita de um professor que não apresente tais dificuldades, isso significa que precisamos formar profissionais que busquem ter autonomia nos contextos educativos, que se vejam e se reconheçam como pessoas que têm importante parcela de contribuição a oferecer às crianças com quem convivem e interagem, que não são meros aplicadores de técnicas, mas professores que buscam de forma integrada e coerente a necessária articulação dos pressupostos teóricos e práticos. A formação desses profissionais precisa tratar da aprendizagem e desenvolvimento da criança de modo que eles não precisem se questionar se devem ou não alimentar as crianças ou trocar-lhes as fraldas, se eles ou outros é que devem realizar tal tarefa.

Tudo isso pode ser possível se os professores forem levados a entender que a dimensão do cuidar é tão importante quanto qual- 
quer outra. Portanto, mesmo ao nível da creche as idéias ora expostas precisam estar na representação social dos nossos profissionais docentes, como algo essencial a fazer para o desenvolvimento das crianças e para a vinculação afetiva delas com os professores. Consideramos que essa é uma alternativa de trabalho que, na formação inicial, contribui para formar pessoas que sejam críticas, capazes de se posicionar, de fazer opções para que possam trabalhar no mesmo sentido com as crianças.

Concordando com essa visão, outro formador por nós entrevistado sobre o problema da separação cuidar-educar, posicionou-se da seguinte forma:

(...) a questão não está tanto na dimensão da formação, mas na dimensão social da representação do que é um educador da infância. A formação de educadora era uma coisa para quem não tinha jeito pra fazer mais nada. Ser educadora era um primeiro passo para ser boa mãe e, portanto, a dimensão do cuidar estava muito no imaginário social do ser educador de infância.

A revisão na história nos revela que a ênfase na pré-escola com "função pedagógica" estimulou nos professores e nos cursos de formação inicial uma preparação do profissional para o "ensino", centrada na preocupação com os conteúdos escolares. Ora, como fazer isso com crianças que ainda não aprenderam a falar, muito menos a escrever? Sendo assim, o professor que vai lidar com as crianças menores não poderá "ensinar conteúdos"; ele vai apenas "cuidar", ou seja, desenvolver tarefas semelhantes às desenvolvidas pelas mães e babás. E para fazer isso é necessária uma formação profissional em nível superior?

Essa compreensão dicotômica de cuidado e educação tem permeado a formação dos profissionais da Educação Infantil, traduzindose em distinções e "hierarquizações" das funções desempenhadas pelos professores no interior das instituições. Tal visão amplia-se para os espaços de organização política da categoria profissional, enfraquecendo a participação dos profissionais da Educação Infantil que, por considerarem que desempenham funções menos importantes (apenas "cuidar" de crianças), não se sentem verdadeiramente integrantes dessa categoria.

O que precisa ser compreendido pelos professores é que sua 
tarefa não é "igual" a das mães e babás, não porque esta não tenha importância, mas porque a tarefa docente tem um diferencial fundamental em relação às outras. Ou seja: os professores têm intencionalidade educativa definida em relação às crianças com as quais interagem e, para fazer isso de forma adequada, precisam de uma formação profissional que realmente os capacite para o exercício docente.

Se os professores deixarem de pensar no "ensino de conteúdos escolares" como a única coisa que dá sentido à sua função de professor, a dimensão do cuidado estará presente naturalmente, pois a preocupação passa a ser com a qualidade da interação que eles estabelecem com as crianças, com a interferência positiva que podem fazer na aprendizagem e no desenvolvimento dela, independentemente da idade das crianças ou das atividades realizadas com elas. Se levarmos os professores a perceberem que os resultados do que fazem com as crianças têm importância para a sociedade, não será mais preciso enfatizar discursos sobre a "necessidade de integrar cuidado e educação".

Consideramos que a visão dicotômica de cuidar-educar é algo que pode ir se diluindo a partir da compreensão que o professor tenha não só do que é ensinar ou de como a criança constrói seu conhecimento, mas também da compreensão da qualidade de suas intervenções nas diversas situações vivenciadas pelas crianças no dia-a-dia da instituição.

A separação entre cuidado e educação, que foi e continua sendo disseminada no imaginário dos professores de Educação Infantil, provoca um "enfraquecimento" de sua participação nos fóruns da categoria, por não se sentirem comprometidos com as lutas por melhorias na profissão, por não se sentirem parte dela, porque a natureza histórica do seu trabalho, apresentada no início deste texto, tem esse "rótulo" de atividade de "pouco valor", legitimada pela sociedade e pela própria categoria. Cabe, então, perguntar: a quem interessa essa "desagregação" dos profissionais que hoje fazem parte legalmente da mesma categoria docente?

Diante das análises até aqui construídas, concluímos que tal problema situa-se no âmbito da representação social da profissão, e é nesse âmbito que precisamos buscar essa solução, através da valorização, do reconhecimento da importância social desses profissionais. Nesse sentido, entendemos que a formação docente, especialmente ao nível da formação inicial, tem grande parcela de contribuição a 
oferecer àqueles que fazem do magistério o seu contexto de vida profissional.

\title{
REFERÊNCIAS
}

ARIÈS, P. História social da criança e da família. Rio de Janeiro: Guanabara, 1981.

DEL PRIORE, M. História da criança no Brasil. São Paulo: Contexto, 1998.

GAGNEBIN, J. M. Sete aulas sobre linguagem, memória e história. Rio de Janeiro: Imago, 1997.

HEYWOOD, C. Uma história da infância: da Idade Média à época contemporânea no Ocidente. Porto Alegre: Artmed, 2004.

KISHIMOTO, T. M. Política de formação profissional para a educação infantil: Pedagogia e Normal Superior. Revista Educação \& Sociedade, ano xx, n. 68, p. 61-79, dez. 1999.

KRAMER, S. A política do pré-escolar no Brasil: a arte do disfarce. Rio de Janeiro, Achimé: 1992.

. (Org.). Com a pré-escola nas mãos - uma alternativa curricular para a educação infantil. São Paulo: Ática, 1993.

KUHLMANN JUNIOR, M. Infância e educação infantil: uma abordagem histórica. Porto Alegre: Mediação, 1998.

MARCILIO, M. L. A roda dos expostos e a criança abandonada na História do Brasil. In: FREITAS, M. C. (Org.). História social da infância no Brasil. São Paulo: Cortez, 1997. p.51-76.

MONARCA, C. Educação da infância brasileira - 1875 - 1983. Campinas: Autores Associados, 2001.

SACRISTÁN, J. G. Consciência e ação sobre a prática como libertação profissional dos professores. In: NÓVOA, A. (Org.). Profissão professor. Portugal: Porto, 1991. p. 61-92. (Coleção Ciências da Educação)

TARDIF, M. Saberes docentes e formação profissional. 2. ed. Petrópolis: Vozes, 2002.

\author{
Encaminhado em: 30/10/07 \\ Aceito em: 10/11/07
}

